\title{
Sensory characterization of pinni - a milk cereal based sweet using quantitative descriptive analysis and principal component analysis
}

\author{
Ravinder Singh, Writhdhama Prasad and Kaushik Khamrui
}

Received: 18 December 2018 / Accepted: 12 February 2019 / Published online: 22 June 2019

(C) Indian Dairy Association (India) 2019

\begin{abstract}
Pinni is a popular traditional milk-cereal based sweet of northern states of India viz., Punjab, Haryana and Delhi. Market samples were collected and were evaluated for various quality attributes. Quantitative Descriptive Analysis revealed significant difference $(\mathrm{p}<0.05)$ in sensorial, physico-chemical, textural attributes of pinni among the market samples. Principal Component Analysis identified key six components comprising of shape, crumbliness, cooked flavour, colour, firmness, oxidized flavour, gumminess, chewiness, cohesiveness, surface appearance and coating and moisture absorption, which governed $78.66 \%$ of the variation in the sensory scores of pinni. Hence, these attributes may be given prime importance while developing technology for industrial scale production of pinni.
\end{abstract}

Keywords: Quantitative descriptive analysis, Principal component analysis, Pinni, Sensory evaluation

\section{Introduction}

Pinni is a traditional dessert popular in northern part of Indian subcontinent. It is prepared by roasting cereal flours mainly

Ravinder Singh, Writhdhama Prasad and Kaushik Khamrui ( $\square$ ) Dairy Technology Division, National Dairy Research Institute, Karnal 132 001, Haryana, India

Email: kkhamrui@gmail.com

Phone: 0184 2259242, Fax: 01842250042 wheat, gram, black lentil flour with added khoa (desiccated milk) and sugar (Talwar and Brar, 2015). Pinni is characterized by light brown colour with grainy texture and pleasant flavour coupled with excellent nutritive value. Pinni is usually prepared during winter and consumed as a dense source of energy, especially by lactating mothers, besides being enjoyed by young ones and adults. Traditionally, pinni is produced at home, but with urbanization and industrialization, it is now manufactured at small scale by food industries in India. Popularity of this product is increasing day by day and sporadic information is available regarding chemical composition and manufacturing process, but practically nothing is known about the sensorial attributes of this delicacy (Talwar and Brar, 2015). Probably due to the absence of any regulatory standard, variations in ingredients quality, recipe and storage temperature of the final product the composition of pinni available in the market widely (Talwar and Brar, 2015). Also, information on the desirable sensory characteristics of this delicacy is also not properly documented. As sensory quality is the driving force for consumer acceptance hence characterization of sensory attributes of the product is crucial to develop a product that meets consumer expectation (Desai et al. 2013).

Quantitative Descriptive Analysis (QDA) approach has been recognized as a tool for measurement and optimization of sensory attributes of various food and dairy products (Stone and Sidel, 1998). In this technique, the panel members are trained to measure the specific quality attributes of the product to obtain quantitative product description which can be analyzed statistically. QDA has been successfully used as technique for sensory evaluation of food products such as UHT milk (Chapman et al. 2001), chocolate milk (Thompson et al. 2004), soy milk (Keast and Lau, 2006), whey and soy proteins (Drake et al. 2007), fermented food products (Ghosh and Chattopadhyay, 2010), yoghurt (Desai et al. 2013) doda burfi (Chawla et al. 2014) and cham-cham (Puri et al. 2015).

Principal component analysis (PCA) is a multivariate statistical analytical technique applied to sensory data to reduce the set of dependent variables (attributes) to a smaller set of underlying variables (called factors) based on patterns of correlation among the original variables (Lawless and Heymann, 1998). QDA and PCA studies on doda burfi revealed that two principal 
components explained $80.50 \%$ of the total variation (Chawla et al. 2014). PC1 was consisted of colour, glossiness, cohesive texture and caramelized flavour and overall acceptability whereas colour, granularity and gumminess were the factors of PC2. Puri et al. (2015) conducted market survey for cham-cham collected from four different locations known for their excellence in chamcham production for sensory characterization using QDA and PCA.

Rapid urbanization and globalization has triggered large-scale marketing of traditional food items like pinni, hence the technology for the production of this delicacy is needed to be standardized for producing it on commercial scale. Before this, the key sensorial attributes that contributes to the acceptability of pinni needs to be identified as they are mainly determined by the manufacturing process adopted. The objective of this study was to estimate the extent of variation in the product collected from different pinni producing centres and to find out the principal sensorial descriptors necessary to explain the desirable sensory attributes of pinni using QDA and PCA.

\section{Materials and methods}

Sample collection: A total of 32 samples, eight each from four cities of North India i.e., Karnal, Amritsar, Ludhiana and Delhi, known for their excellence in pinni production were collected thrice. Product was procured on the day of manufacture in sterilized rigid containers to retard physicochemical and microbiological changes and transported ambient temperature $\left(30 \pm 2{ }^{\circ} \mathrm{C}\right)$ to the laboratory so as to minimize the chances of error in the sensory results.

Sensory analyses: The terms for sensory evaluation of pinni samples were developed by nine member trained sensory evaluation panelist aged between 28-52 years. They provided independent observations on randomized samples of pinni using QDA methodology (Lawless and Heyman, 1998). The judges had previous experience in sensory evaluation of milk products. The ballot development for sensory evaluation was accomplished in seven working sessions. After the terminology development phase, the panelists were trained for the evaluation of pinni. Training consisted of evaluating pinni by use of the descriptive terms developed to describe and quantify appearance, flavour and texture of pinni. Attributes were quantified with an intensity rating scale from 0 to 10 ; where $0=$ attribute not detected and 10 $=$ attribute extremely strong. A line of $10 \mathrm{~cm}$ ranging from 0 to 10 points was drawn with marking interval of $1 \mathrm{~cm}$ for evaluation and reporting sensory results. Panelists were asked to mark a vertical linear mark indicating the sample number along the horizontal linear scale for a particular attribute. Overall quality rating was measured with a scale of 1 to 10 , where $<6$ was considered "poor", 6 to 7 was "fair", and 8 to 10 was "good" (Chapman et al. 2001). This procedure was repeated until panel consensus was achieved. Each sample was served at a time with deionised water. At each testing period, two intact pieces two intact pieces of samples (tempered to $20 \pm 1$ ÚC) were presented coded with random three digit numbers in closed glass containers to panel members seated in individual booths. The descriptors used for evaluating appearance were colour, shape, surface appearance, surface coating for flavor, cereal like/doughy, ghee aroma, rancid, oxidized, stale, cooked flavor, sweetness, off flavour were used. Texture descriptor used in the study was firmness, crumbliness, sandy/granular, gumminess, chewiness, cohesiveness, moisture absorption. An additional attributes viz., overall acceptability was added along with other descriptors to judge the extent of liking of the product. PCA is a multivariate technique in which a structure is extracted from a correlation matrix, based on the scores obtained by descriptive analysis technique several dependent variables could be correlated using this technique. By identifying the pattern of correlation among the dependent variables, a new variable is generated in PCA which is called as factor for the group of correlated original attributes. In the subsequent stages second and third groups are also identified with derivation of factors for each, based on residual variance. PCA provides factor loading and factor scores. The former is represented as correlations of attribute with new dimensions while the latter as values of products on new dimensions. For interpretation of dimensions, factor loadings are essential and the factor scores illustrate the relative positions among the products in a map (Jolliffe, 2005). Hence, to simplify the data and eliminate descriptor redundancies transformation of original dependent variable into uncorrelated dimensions is carried out using PCA.

Statistical Analysis: of pinni samples was analyzed Analysis of Variance (ANOVA) was done on the data generated from market survey to check the difference in means. Duncan's post hoc test was used to determine the difference in individual mean values. Principal Component Analysis (PCA) of the data obtained was carried out using SPSS (version 20.0). The principal components were extracted based on Eigen values which are greater than 1 and the varimax method was used to rotate the solutions. Normalization was done by Kaiser Method following the principle described by Lawless and Heyman, (1998).

\section{Results and discussion}

\section{Quantitative Descriptive Analyses (QDA)}

Specific terms which were used for QDA to evaluate the samples were generated after discussion held with trained panellists. The lists of terminologies (lexicons) for evaluating sensory attributes of pinni were finally refined and are presented in Table 1 . In Table 2 the mean panellist ratings of organoleptic quality of market samples of pinni related to its appearance, flavour, texture attributes and overall acceptability are provided. 
Fig. 1 Sensory profiles of market samples of pinni from four different groups. Individual attributes are positioned like the spokes of a wheel around a center zero, or not detected) point, with the spokes representing attribute intensity scales, with higher (more intense) values radiating outward.

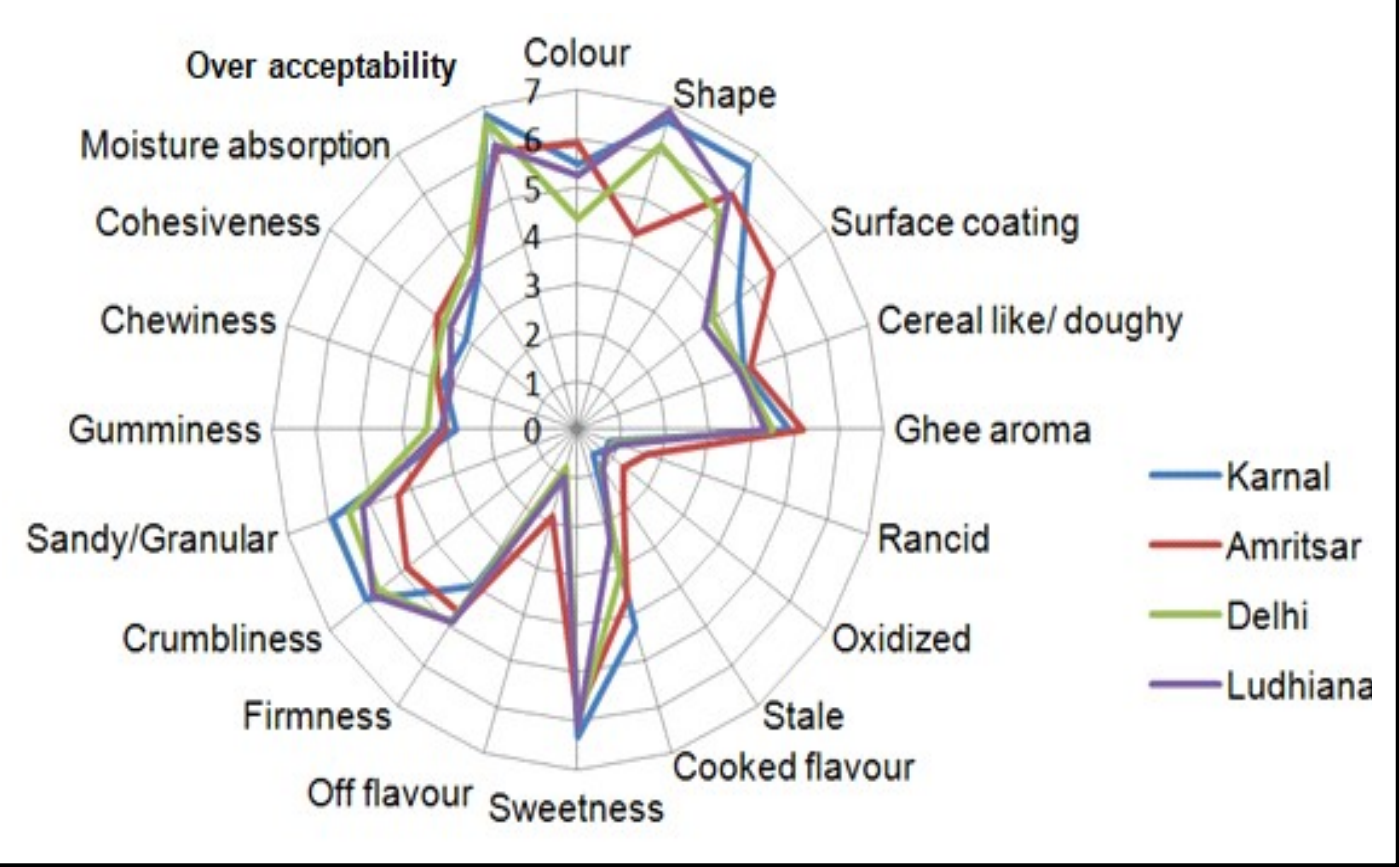

Shape, stale, cooked flavour, crumbliness and sandy/granular sensorial attribute of the samples varied significantly $(p<0.05)$ among the four groups studied i.e., sensory scores for shape of the sample varied significantly between Amritsar and other three groups. Shape of the product varied from cylindrical to round, round being the most desirable and common one. Panellists also observed stale flavour as one of the major difference in sensory attributes while marking on descriptive scale. Stale flavour in Amritsar group was significantly different $(\mathrm{p}<0.05)$ only from Karnal group. Stale flavour develops due to prolonged storage of samples of pinni, the reason of stale flavour is initiation of many undesirable chemical changes e.g., fat oxidation protein degradation etc (Chawla et al. (2015).

'Cooked flavour' of Ludhiana group sample was different $(p<0.05)$ from Karnal group, which could be attributed to the processing steps involved in pinni preparation. Pinni is prepared by roasting wheat flour in ghee and roasting is done until typical flavour is developed. This process sometime leads to over cooking of product, which results in development of cooked flavour. Crumbliness textural attribute of Amritsar group of samples was significantly $(p<0.05)$ different from Karnal. Sandy/Granular texture of Amritsar group was significantly different from Karnal and Delhi group. Sandy/granular texture is due to the presence of coarse sand like particle in pinni may be due to variation in wheat flour (refined or whole) used in making pinni place to place.

To create a visual profile or fingerprinting of product attributes, spider plots was created by plotting average intensity values on an appropriate scale, and then joining the points (Figure 1). This plot illustrates that 'shape' of Ludhiana and Karnal group samples was highly towards round side which is a desirable characteristic of this attribute and samples of Amritsar had deviated from round shape and obtained lowest scores. As can be seen, stale flavour was more in Amritsar group from remaining three groups. Score for 'cooked flavour' was highest for Karnal group of samples probably due to the more roasting in case of this group of samples then remaining ones. 'Crumbliness' texture was highest in Karnal and Ludhiana group of samples and lowest in Amritsar group samples. 'Sandy/granular' texture was also more in Karnal group and lowest in Amritsar group. There was non-significant ( $p>0.05)$ difference in 'colour', 'surface coating', 'ghee aroma', 'rancid', 'oxidized', 'sweetness', 'off flavour', 'firmness', 'gumminess', 'chewiness', 'cohesiveness' and moisture absorption in the samples collected from four different cities. Among the twenty lexicons generated through discussion among the panel members nine i.e., surface colour, doughy, rancid, stale, off flavour, granularity, firmness, chewiness and gumminess are common with sensory lexicon of doda burfi. This reveals thereby the organoleptical differences between doda burfi and pinni and justifies the need for development of product specific semantics for describing optimum sensorial quality. Desirable sensory attributes of pinni was found to be round shape with dark brown colour, absence of interstitial spaces or bumps on the surface, presence of moderate degree of coating with dry fruit on product's surface, free from rancid, oxidized, doughy and stale flavour with moderate degree of firmness, chewiness, cohesiveness and cooked flavour.

\section{Principal components analysis (PCA)}

PCA was applied to the mean attribute ratings listed in Table 1 to simplify interpretation of data from 21 attributes measured on 32 
Fig. 2 Cumulative variance plot and eigen values of six extracted Principal c o $\mathrm{m} \mathrm{p}$ o $\mathrm{n}$ e $\mathrm{n} \mathrm{t} \mathrm{s}$ generated using PCA

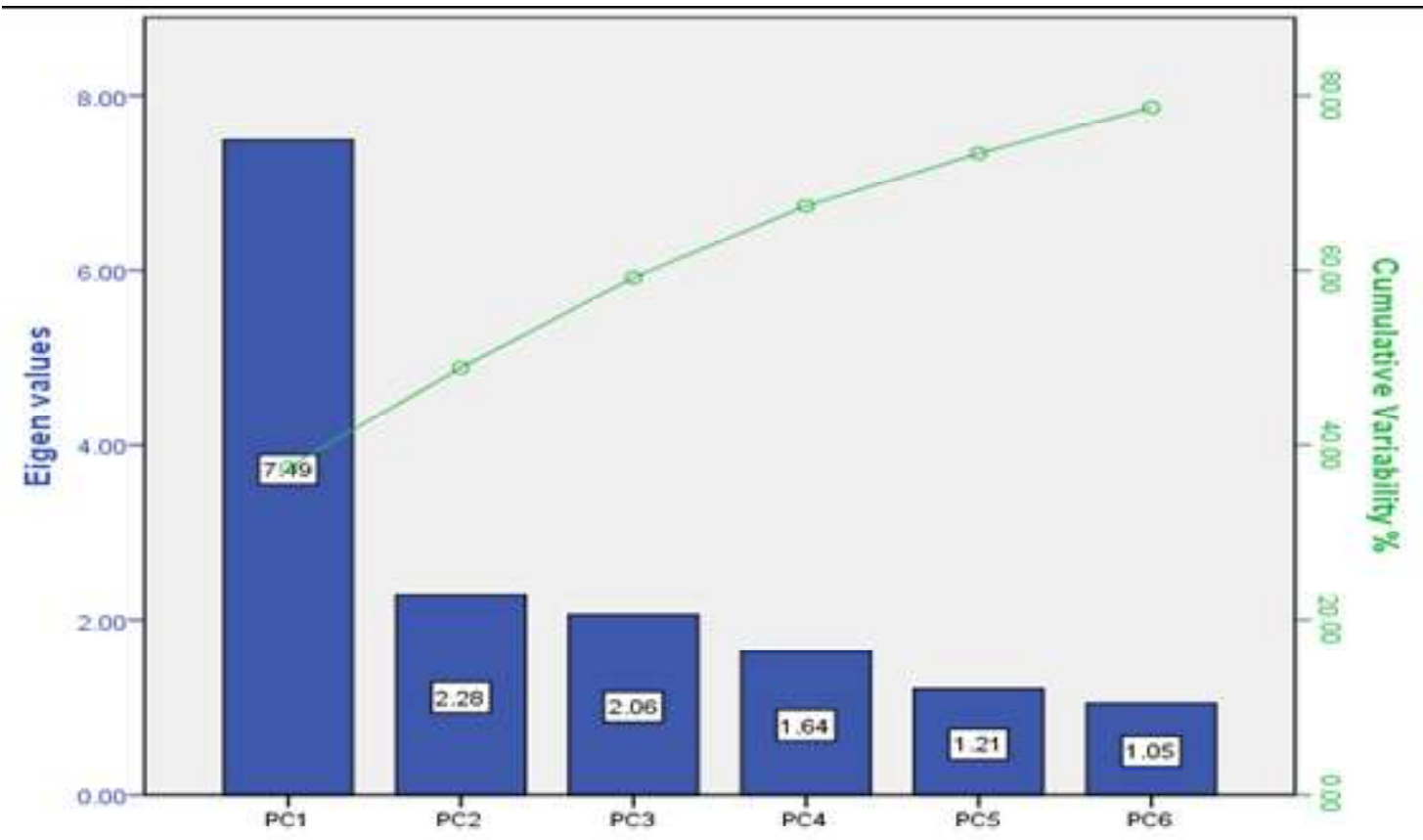

Table 1. Descriptors with definition used to explain the desirable quality parameters for Pinni

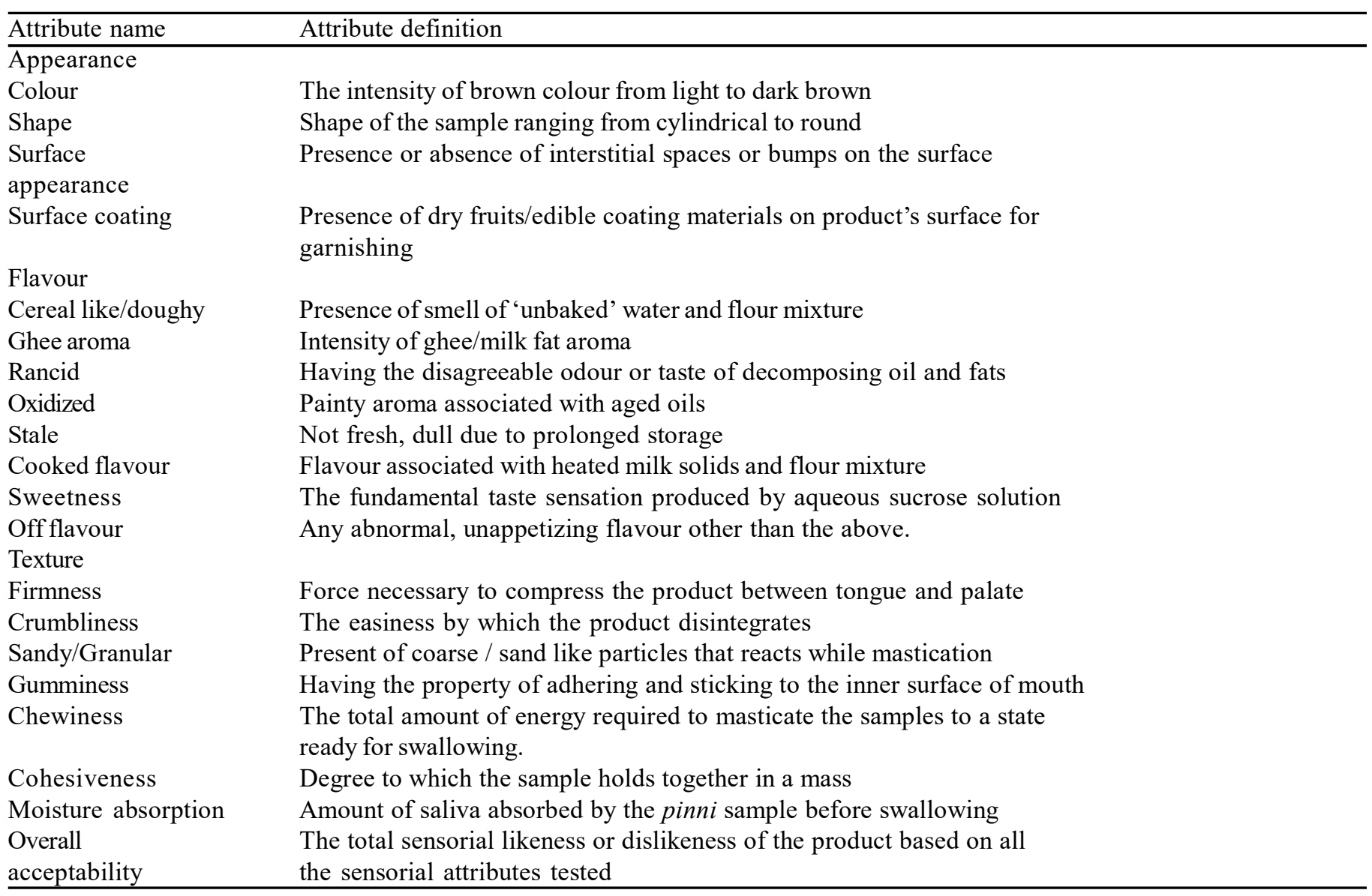

products from four different groups. To acquire specific knowledge about primitive factors having critical importance 

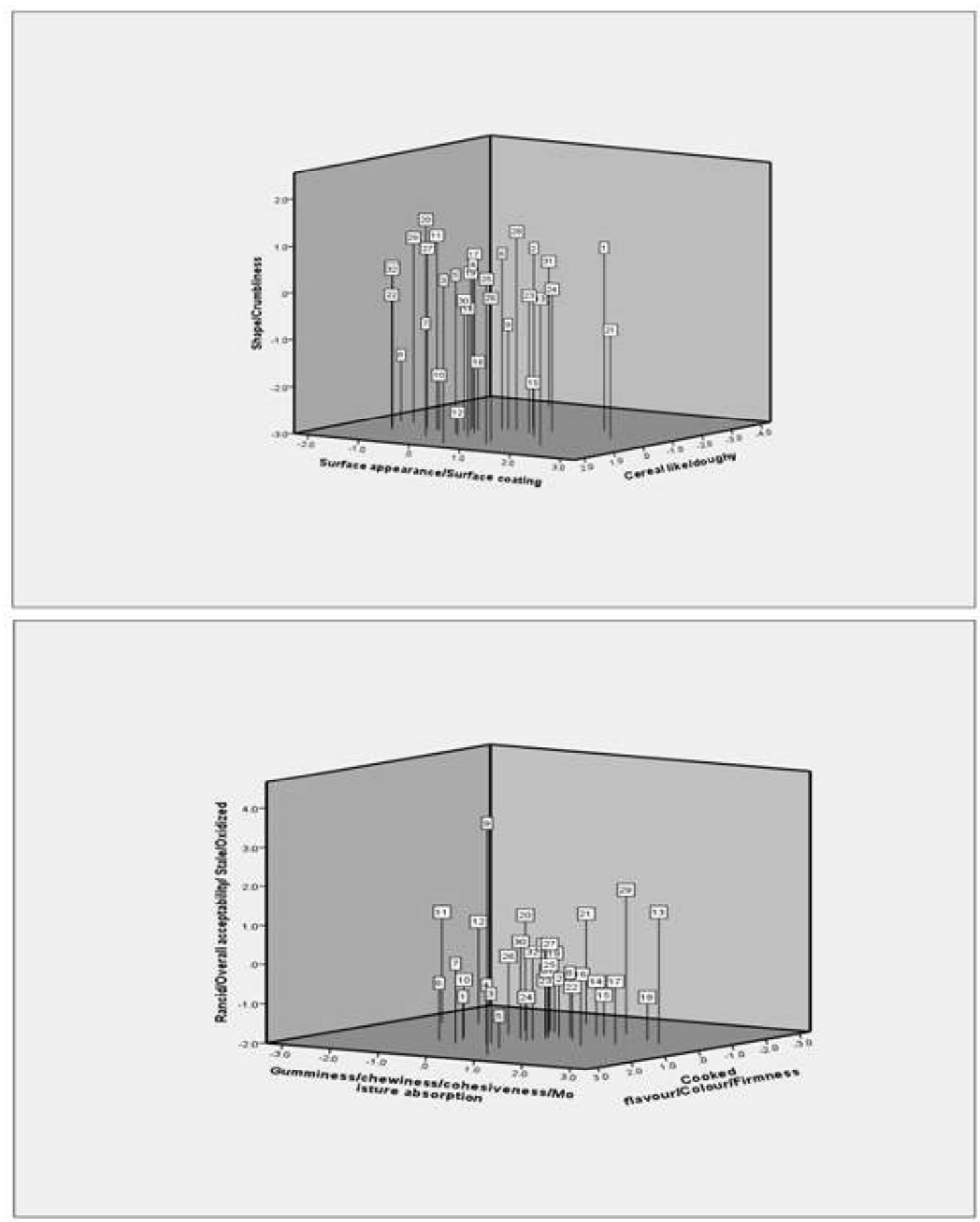

Fig. 3 Three-dimensional plot showing factor scores of market samples of pinni on Varimax rotated PC axis (a) PC1, PC2, PC3 and (b) PC4, PC5, PC6. Labels: Karnal (1-8), Amritsar (9-16), Delhi (17-24), Ludhiana (2532).

among the sensorial descriptors i.e., PCs were extracted based on maximum variance values. Among all the PCs extracted, six PCs having eigen values $>1$ (Kaiser criterion) explaining 78.66\% of the total variance in the sensory data set were taken for further analysis. The results revealed that on the basis of eigen vector loadings, first PC with an eigen value of 7.50 was able to explain
$37.47 \%$ of the total variation (Fig. 2) whereas second PC with an eigen value 2.28 explained $11.40 \%$ of the variation and third PC with eigen value 2.1 explained $10.31 \%$ first three PC's (PC1, PC2 and PC3) explained $59.18 \%$ of the total variation. Fourth PC with eigen value of 1.64 was able to explain $8.19 \%$ variation. Fifth PC with eigen value of 1.211 was able explain $6.05 \%$ variation and 
Table 2. Mean sensory scores showing differences between groups ${ }^{1}$

\begin{tabular}{|c|c|c|c|c|}
\hline Attributes & Karnal & Amritsar & Delhi & Ludhiana \\
\hline Colour & $5.44^{\mathrm{a}} \pm 0.61$ & $5.91^{\mathrm{a}} \pm 0.85$ & $4.34^{a} \pm 0.52$ & $5.23^{a} \pm 0.52$ \\
\hline Shape & $6.66^{\mathrm{a}} \pm 0.74$ & $4.24^{\mathrm{b}} \pm 0.67$ & $6.16^{\mathrm{a}} \pm 0.39$ & $6.90^{\mathrm{a}} \pm 0.29$ \\
\hline Surface appearance & $6.71^{\mathrm{a}} \pm 0.39$ & $6.01^{\mathrm{a}} \pm 0.53$ & $5.53^{a} \pm 0.53$ & $5.94^{\mathrm{a}} \pm 0.46$ \\
\hline Cereal like/doughy & $4.02^{\mathrm{a}} \pm 0.28$ & $4.14^{\mathrm{a}} \pm 0.16$ & $3.99^{a} \pm 0.18$ & $4.19^{\mathrm{a}} \pm 0.33$ \\
\hline Ghee aroma & $4.86^{\mathrm{a}} \pm 0.16$ & $5.16^{\mathrm{a}} \pm 0.33$ & $4.48^{a} \pm 0.23$ & $4.33^{\mathrm{a}} \pm 0.39$ \\
\hline Stale flavour & $0.62^{\mathrm{a}} \pm 0.06$ & $1.76^{\mathrm{b}} \pm 0.58$ & $0.94^{\mathrm{ab}} \pm 0.17$ & $1.01^{\mathrm{ab}} \pm 0.29$ \\
\hline Cooked flavour & $4.28^{a} \pm 0.35$ & $3.65^{\mathrm{ab}} \pm 0.69$ & $3.14^{\mathrm{ab}} \pm 0.31$ & $2.43^{\mathrm{b}} \pm 0.37$ \\
\hline Sweetness & $6.34^{\mathrm{a}} \pm 0.21$ & $5.85^{\mathrm{a}} \pm 0.37$ & $6.04^{\mathrm{a}} \pm 0.22$ & $6.13^{a} \pm 0.12$ \\
\hline Off flavour & $1.00^{\mathrm{a}} \pm 0.22$ & $1.85^{\mathrm{a}} \pm 0.60$ & $0.82^{\mathrm{a}} \pm 0.17$ & $1.02^{\mathrm{a}} \pm 0.32$ \\
\hline Firmness & $4.02^{\mathrm{a}} \pm 0.23$ & $4.64^{\mathrm{a}} \pm 0.42$ & $4.89^{a} \pm 0.25$ & $4.87^{\mathrm{a}} \pm 0.22$ \\
\hline Chewiness & $3.21^{\mathrm{a}} \pm 0.24$ & $3.39^{\mathrm{a}} \pm 0.64$ & $3.49^{\mathrm{a}} \pm 0.30$ & $3.07^{\mathrm{a}} \pm 0.23$ \\
\hline Cohesiveness & $3.17^{\mathrm{a}} \pm 0.23$ & $4.01^{\mathrm{a}} \pm 0.46$ & $3.77^{\mathrm{a}} \pm 0.31$ & $3.61^{\mathrm{a}} \pm 0.16$ \\
\hline Moisture absorption & $3.87^{\mathrm{a}} \pm 0.21$ & $4.29^{\mathrm{a}} \pm 0.38$ & $4.27^{\mathrm{a}} \pm 0.17$ & $3.97^{\mathrm{a}} \pm 0.19$ \\
\hline Overall acceptability & $6.80^{\mathrm{a}} \pm 0.21$ & $6.07^{\mathrm{a}} \pm 0.49$ & $6.70^{\mathrm{a}} \pm 0.18$ & $6.15^{\mathrm{a}} \pm 0.22$ \\
\hline
\end{tabular}

${ }^{1}$ Mean sensory scores of pinni samples collected from eight different shops of four cities (Mean $\pm \mathrm{SE}$ )

ANOVA and Duncan post hoc test was applied to the descriptive sensory score data to obtain difference in means

${ }^{\mathrm{ab}}$ Means in the row followed by different letters represents significant differences $(\mathrm{P}<0.05)$

Table 3. Varimax rotated principal component factor loadings for Pinni attributes

\begin{tabular}{|c|c|c|c|c|c|c|}
\hline Attributes & $\mathrm{PCl}$ & $\mathrm{PC} 2$ & $\mathrm{PC3}$ & $\mathrm{PC4}$ & PC5 & PC6 \\
\hline Colour & 0.199 & 0.209 & $0.688^{*}$ & 0.070 & -0.129 & 0.162 \\
\hline Shape & -0.131 & -0.086 & 0.158 & -0.147 & $0.834 *$ & 0.150 \\
\hline Surface appearance & -0.139 & -0.220 & 0.275 & $-0.807 *$ & -0.199 & -0.030 \\
\hline Surface coating & -0.037 & 0.023 & 0.183 & $0.780 *$ & -0.374 & 0.073 \\
\hline Cereal like/ doughy & 0.034 & 0.089 & -0.015 & 0.004 & 0.064 & $0.922 *$ \\
\hline Ghee aroma & 0.247 & 0.192 & 0.212 & 0.455 & -0.184 & 0.561 \\
\hline Stale & 0.463 & $0.683^{*}$ & 0.225 & 0.260 & -0.154 & -0.002 \\
\hline Cooked flavour & 0.408 & 0.123 & $0.712 *$ & 0.311 & -0.042 & 0.163 \\
\hline Sweetness & -0.129 & -0.015 & 0.638 & -0.375 & 0.245 & -0.032 \\
\hline Off flavour & 0.376 & 0.764 & 0.250 & 0.146 & -0.257 & 0.173 \\
\hline Firmness & -0.065 & -0.327 & $-0.665^{*}$ & 0.064 & -0.134 & 0.139 \\
\hline Chewiness & $0.898^{*}$ & 0.074 & 0.130 & 0.201 & 0.016 & 0.188 \\
\hline Cohesiveness & $0.849 *$ & 0.001 & 0.008 & -0.055 & -0.275 & 0.001 \\
\hline Moisture absorption & $0.770^{*}$ & 0.324 & 0.042 & -0.079 & -0.180 & -0.133 \\
\hline Overall acceptability & -0.118 & $-0.866^{*}$ & -0.210 & -0.040 & 0.018 & -0.137 \\
\hline Variance explained $^{1}$ & $20.51 \%$ & $18.90 \%$ & $12.14 \%$ & $9.99 \%$ & $9.95 \%$ & $7.13 \%$ \\
\hline
\end{tabular}

Six PC were extracted by applying PCA on the mean values of descriptive sensory scores

* Most important attributes; ${ }^{1}$ Refers to percent variance explained 
sixth PC having eigen value of 1.047 explained 5.23\% variability. PCs were rotated using varimax rotations for closer alignment with original variables (Lawless and Heymann, 1998). Rotation of variables resulted in factor loading which represents correlation between PC and the original attribute measured as shown in Table 3. High factor loading values that are marked with asterisk were found to be of paramount importance. Absolute value of factor loadings corresponding to each sensory attribute decides the relation between principal component and that specific sensory attribute (Chapman et al. 2001). It could be observed that PC1 was found to be entirely related to the gumminess, chewiness, cohesiveness and moisture absorption as the loadings had maximum absolute values. PC2 had large loadings for rancid flavour, overall acceptability, stale flavour and oxidized flavour. PC3 was found to be related to cooked flavour, colour and firmness. PC4 was found be related to the surface appearance

Table 4. Factor scores for market samples of pinni.

\begin{tabular}{|c|c|c|c|c|c|c|}
\hline Shop codes & $\begin{array}{l}\text { PC1Gumminess/ } \\
\text { chewiness/ } \\
\text { cohesiveness/ } \\
\text { Moisture } \\
\text { absorption }\end{array}$ & $\begin{array}{l}\text { PC2 } \\
\text { Rancid/ } \\
\text { Overall } \\
\text { acceptability/ } \\
\text { Stale/ Oxidized }\end{array}$ & $\begin{array}{l}\text { PC3 } \\
\text { Cooked } \\
\text { flavour/ } \\
\text { Colour/ } \\
\text { Firmness }\end{array}$ & $\begin{array}{l}\text { PC4 } \\
\text { Surface } \\
\text { appearance/ } \\
\text { Surface } \\
\text { coating }\end{array}$ & $\begin{array}{l}\text { PC5 } \\
\text { Shape/ } \\
\text { Crumbliness }\end{array}$ & $\begin{array}{c}\text { PC6 } \\
\text { Cereal } \\
\text { like/ } \\
\text { doughy }\end{array}$ \\
\hline$\overline{\mathrm{K} 1}$ & -0.862 & -0.907 & 1.015 & 1.627 & 0.903 & -1.503 \\
\hline K2 & 0.248 & -0.527 & -0.253 & 1.078 & 1.012 & -0.058 \\
\hline K3 & -0.188 & -0.748 & 1.141 & 0.375 & 0.473 & 1.804 \\
\hline K4 & -0.176 & -0.501 & 1.286 & -0.309 & 0.471 & -0.368 \\
\hline K5 & 0.301 & -1.195 & 1.599 & -0.161 & 0.364 & 0.474 \\
\hline K6 & -1.127 & -0.544 & 1.339 & 0.163 & 0.747 & -0.543 \\
\hline K7 & -0.674 & 0.019 & 1.507 & -0.308 & -0.580 & 1.235 \\
\hline K8 & 0.328 & -0.400 & -0.475 & -1.724 & -1.593 & -0.350 \\
\hline A9 & 0.691 & 3.903 & 2.508 & 0.288 & -0.757 & -0.536 \\
\hline A10 & -1.082 & -0.550 & 0.671 & -0.552 & -1.816 & 0.364 \\
\hline A11 & -2.526 & 0.829 & -0.742 & -0.656 & 1.138 & 0.261 \\
\hline A12 & -2.006 & 0.590 & -1.086 & -0.006 & -2.512 & 0.674 \\
\hline A13 & 2.196 & 1.347 & -0.443 & 1.810 & 0.126 & 0.975 \\
\hline A14 & 0.668 & -0.626 & -0.769 & 0.237 & -0.271 & 0.740 \\
\hline A15 & 0.767 & -0.972 & -0.849 & 0.550 & -2.022 & -0.941 \\
\hline A16 & 1.248 & -0.202 & 0.522 & -0.076 & -1.549 & -0.147 \\
\hline D17 & 1.605 & -0.424 & 0.0002 & 0.096 & 0.821 & 0.274 \\
\hline D18 & 1.747 & -0.910 & -0.742 & -1.260 & 0.465 & 0.746 \\
\hline D19 & -0.229 & -0.003 & -0.804 & -0.169 & 0.343 & -0.059 \\
\hline D20 & -0.771 & 0.934 & -0.715 & -1.120 & 1.372 & -0.163 \\
\hline D21 & -0.461 & 0.804 & -2.083 & 2.264 & -0.690 & -0.629 \\
\hline D22 & 0.670 & -0.661 & -0.053 & -1.627 & -0.237 & 0.133 \\
\hline D23 & 0.222 & -0.521 & 0.098 & 0.807 & -0.072 & -0.365 \\
\hline D24 & 0.075 & -0.907 & 0.462 & 0.987 & 0.027 & -0.830 \\
\hline L25 & -0.336 & -0.309 & -0.815 & 0.984 & 0.509 & 1.396 \\
\hline L26 & -0.710 & -0.030 & -0.119 & 0.860 & 0.047 & 1.027 \\
\hline L27 & -0.416 & 0.204 & -0.930 & -0.801 & 0.864 & 0.332 \\
\hline L28 & -0.155 & 0.284 & -0.428 & 0.437 & 1.232 & -0.575 \\
\hline L29 & 0.928 & 1.667 & -1.283 & -1.428 & 0.956 & -0.264 \\
\hline L30 & -0.164 & 0.465 & 0.294 & -0.234 & -0.231 & 0.062 \\
\hline L31 & 0.113 & -0.321 & -0.129 & -0.780 & 0.080 & -3.749 \\
\hline L32 & 0.078 & 0.217 & 0.279 & -1.352 & 0.378 & 0.584 \\
\hline \multicolumn{2}{|c|}{ Variance explained $20.51 \%$} & $18.90 \%$ & $12.14 \%$ & $9.99 \%$ & $9.95 \%$ & $7.13 \%$ \\
\hline
\end{tabular}

K1-K8: sample codes for Karnal, A9-A16: sample codes for Amritsar, D17-D24: sample codes for Delhi, L25-D32: sample codes for Delhi.

Factor scores were generated by applying PCA on descriptive sensory score data

${ }^{a}$ Refers to percent variance explained 
and surface coating. PC5 was largely related to shape and crumbliness. While PC6 was found to be influenced only by cereal like/doughy flavour.

The factor scores for market samples of pinni are presented in Table 4. Coxon (1982) observed that the factor score values could be utilized for the purpose to position or specify the location of all the samples along the varimax rotated PC. Hence, the three dimensional graphs generated depicting the position of different samples along four PC generated (Fig $3 a$ and $3 b$ ). Products that are similar are positioned in close proximity to one another in the graph, and products that are very different are far apart (Jolliffe, 2005).

It can be observed from Fig. 3a that samples from Amritsar and Delhi are in close proximity with each other, having high factor score values (A $13=2.196$ and D $18=1.747$ ) for 'gumminess/ chewiness /cohesiveness/moisture absorption' axis as compared to Karnal and Ludhiana groups which had less gumminess and chewiness value. Rancid, stale and oxidized flavour factor score of Amritsar and Ludhiana group was more $(\mathrm{A} 9=3.903$, A13 = 1.347 and L $29=1.667$ ) which made the sample of these groups less acceptable as compared to Karnal and Delhi groups that had negative factor score values. Cereal/dough like flavour factor score value was more in Ludhiana group as compared to other three groups this factor score value was also undesirable (Figure $3 b)$. Surface appearance was highest factor score value for Karnal at the same time surface coating gained highest value was for Amritsar group. It can also be observed from Fig. $3 b$ that samples of Ludhiana and Karnal groups are in close proximity with each other having high factor score values ( 0.876 to 1.075 ) for shape as compared to Amritsar and Delhi groups which deviated from desirable spherical shape as shown by negative score values. Similar to this work concerning characterization of market samples of pinni, Chawla et al. (2014) conducted descriptive sensory analysis of doda burfi, another khoa based traditional Indian dairy product

\section{Conclusions}

The results of the study suggested that in PC1 (gumminess, chewiness, cohesiveness and moisture absorption) in PC2 (rancid, stale flavour, oxidized flavour and overall acceptability), in PC3 (cooked flavour, colour and firmness) in PC4 (surface appearance and surface coating) in PC5 (shape and crumbliness) and in PC6 (cereal like/doughy) had explained much of the variation in descriptive sensory data. It can clearly be observed from the three-dimensional graphs axes that samples positioned in close proximity with one of the axis has more influence of that particular PC which in turn requires attention during technology development and commercialization of optimized product with desired sensory attributes. PCA identified six key components composed of shape, crumbliness, cooked flavour, colour, firmness, oxidized flavour, gumminess, chewiness, cohesiveness, surface appearance and surface coating and moisture absorption, which governed much of the variation in the sensory scores of pinni. Hence, these attributes may be given prime importance while developing the product technology for industrial scale production. Analysis of sensorial attributes of market samples of pinni revealed significant differences in shape, stale off flavour, cooked flavour, crumbliness and sandy or granular texture among samples from different locations. Among the four cities surveyed, sample collected from Karnal city showed maximum positive loadings and attributes which were undesirable were found either negligible or completely absent.

\section{References}

Chapman KW, Boor KJ (2001) Acceptance of 2\% ultra-pasteurized milk by consumers, 6 to 11 years old. J Dairy Sci 84: 951-954

Chawla R, Patil GR, Singh AK (2014) Sensory characterization of doda burfi (Indian milk cake) using Principal Component Analysis. J Food Sci Technol 51:558-564

Chawla R, Singh AK, Patil GR (2015) Shelf life enhancement of functional doda burfi (indian milk cake) with bio preservatives application. Int J Res Sci Technol 5(2): 26-40

Coxon APM (1982) Three-way and further extensions of the basic model. In the users guide to multidimensional scaling, Heinemann Educational Books, London pp 186-241

Desai NT, Shepard L, Drake MA (2013) Sensory properties and drivers of liking for Greek yogurts. J Dairy Sci 96: 7454-7466

Drake MA, Jones VS, Russell T, Harding R, Gerard PD (2007) Comparison of lexicons for descriptive analysis of whey and soy proteins in New Zealand and the U.S.A., J Sensory Stud 22: 33-452

Ghosh D, Chattopadhyay P (2010) Application of principal component analysis (PCA) as a sensory assessment tool for fermented food products J Food Sci Technol 49: 328-334

Jolliffe I (2005) In: Principal component analysis. John Wiley and Sons Ltd, pp 78-110

Keast R, SJ, Lau JJ (2006) Culture specific variation in the flavour profile of soymilks. J Food Sci71: S567-S572

Lawless HT, Heymann H (1998) Sensory evaluation of food principals and practices. Chapman and Hall, New York, pp 606-608

Puri R, Khamrui K, Khetra Y, Malhotra R, Devraja HC (2015) Quantitative descriptive analysis and principal component analysis for sensory characterization of Indian milk product cham-cham. J Food Sci Technol 53:1238-1246

Stone H, Sidel JL (1998) Quantitative descriptive analysis: developments, applications and the future. Food Technol 52: 48-52

Talwar G, Brar SK (2015) Study of physiochemical, sensory and color properties of pinni variants. Indian J Scie Technol 8:624-629

Thompson JL, Drake MA, Lopetcharat K, Yates MA (2004) Preference mapping of commercial chocolate milks. J Food Scie 69: 406-413 